\title{
FEATURE
}

\section{Testing Telepresence Remote Reference Service via Robotics}

\section{Jeffrey Hartsell-Gundy, Eric O. Johnson, and John Kromer}

\section{Jeffrey Hartsell-Gundy (jeffgundy@ gmail.com) is the former Government Information and Law Librarian at Miami University, Ohio. Eric $\mathbf{O}$. Johnson is Numeric and Spatial Data Services Librarian, Miami University, Oxford, Ohio. John Kromer is Physical Sciences Librarian, Miami University, Oxford, Ohio.}

Reference \& User Services Quarterly, vol. 55, no. 2, pp. 118-21

(c) 2015 American Library Association. All rights reserved.

Permission granted to reproduce for nonprofit, educational use.
Interacting with patrons is the heart of reference services, but it is not always possible to meet face-to-face. This paper details the results of the testing of a telepresence robot for reference services. Telepresence systems allow for two way audio and video communication between remote parties; by combining telepresence with robotics this two way communication can happen anywhere. Adding telepresence capabilities to the existing suit of reference services on offer was meant to expand the reach of librarians throughout the building. However limitations in hardware and software mean the platform is not currently sufficient for reference services.

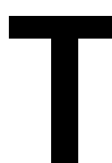

elepresence allows for realtime interaction between two parties over the Internet providing live video and audio communication. Telepresence systems are used for tours, meetings, and any interaction where one party cannot be physically present with others. While the Miami University Libraries currently offer reference services in many formats, such as in-person at our libraries, over the phone, through online chat, email, and via text messaging, a collaboration with the Mechanical Engineering department gave us the chance to experiment with a telepresence robot. It seemed to be an ideal opportunity to test providing remote (roving) reference services to patrons within the library. Through our study we determined what worked, the limitations of the robot, and observed the reactions of patrons. We concluded that this robot has limited usefulness for remote reference service though telepresence seems promising.

\section{LITERATURE REVIEW}

In manufacturing, entertainment, and service industries various systems referred to as robots have been in use for decades. Autonomous and semiautonomous systems build cars, sort inventory, and assist with surgeries. Libraries around the world use automated systems to store, ${ }^{1}$ retrieve, ${ }^{2}$ and digitize books. ${ }^{3}$ While some work has been done using robots in libraries to foster human interaction with patrons ${ }^{4}$ most robots in libraries have been the aforementioned autonomous and semiautonomous systems designed for materials management.

As of 2013 close to half of Americans own a tablet or e-reader, ${ }^{5}$ and more than half own a smartphone. ${ }^{6}$ Such mobile devices are common place among library patrons. The Miami University Libraries circulate iPads and 
Android tablets. Mobile devices are increasingly being used by librarians in roving reference to extend the information seeking capabilities of librarians as they work throughout the library. ${ }^{\top}$

Roving reference is the practice of librarians moving about the library to interact with students. ${ }^{8}$ Roving librarians have increasingly been utilizing mobile technologies to expand the information resources they have access to away from the desk. ${ }^{9}$

The system we tested combines robotics, mobile technologies, and telepresence. The robot used in this experiment is a non-autonomous system which requires a human operator. While this trial was built around testing the robotic hardware the most promising results and directions for future tests were related to the telepresence functionality as an application for roving reference.

\section{THE TRIAL}

The goal of this trial was to see if an ambulatory iPad with video chat could provide a means of roving reference, thus expanding the reach of our reference services within the library. Study space is at a premium in our building and students are often loath to leave a prime spot.

The robot used in this trial was a $\$ 2,500$ Double Robotics telepresence robot which consists of a self-balancing wheeled base (similar to a Segway) supporting a heightadjustable mast that holds an (library-supplied) iPad (see figure 1).

An app runs on the iPad controlling the wheeled base and the telepresence functions. An operator controls the robot through a web interface managed by Double Robotics or an iOS app. Operators can connect to any robot which they have access to from anywhere on Earth with an Internet connection. Using the iPad's front-facing camera, the operator is able to see what the robot "sees" with the operator visible on the iPad screen via their webcam. The iPad's microphone and speakers allow for two-way voice communications.

The trial ran for seven weeks during January and February of 2014 at King Library on the Oxford Campus of Miami University on the first (open study, reference, and circulation) and second (quiet study and stacks) floors. The robot was manned from 9 a.m.-noon and 1-4 p.m. each weekday with operators in their offices on the second and third floors. King was chosen because it is the most visited library on campus. The robot was demonstrated in other libraries, however they are too small to warrant the use of remote services on site.

We advertised the service on the library's website and blog. Additionally we had the robot available at several locations throughout the library, "live" for people to interact with rather than simply waiting for questions to come in through other services.

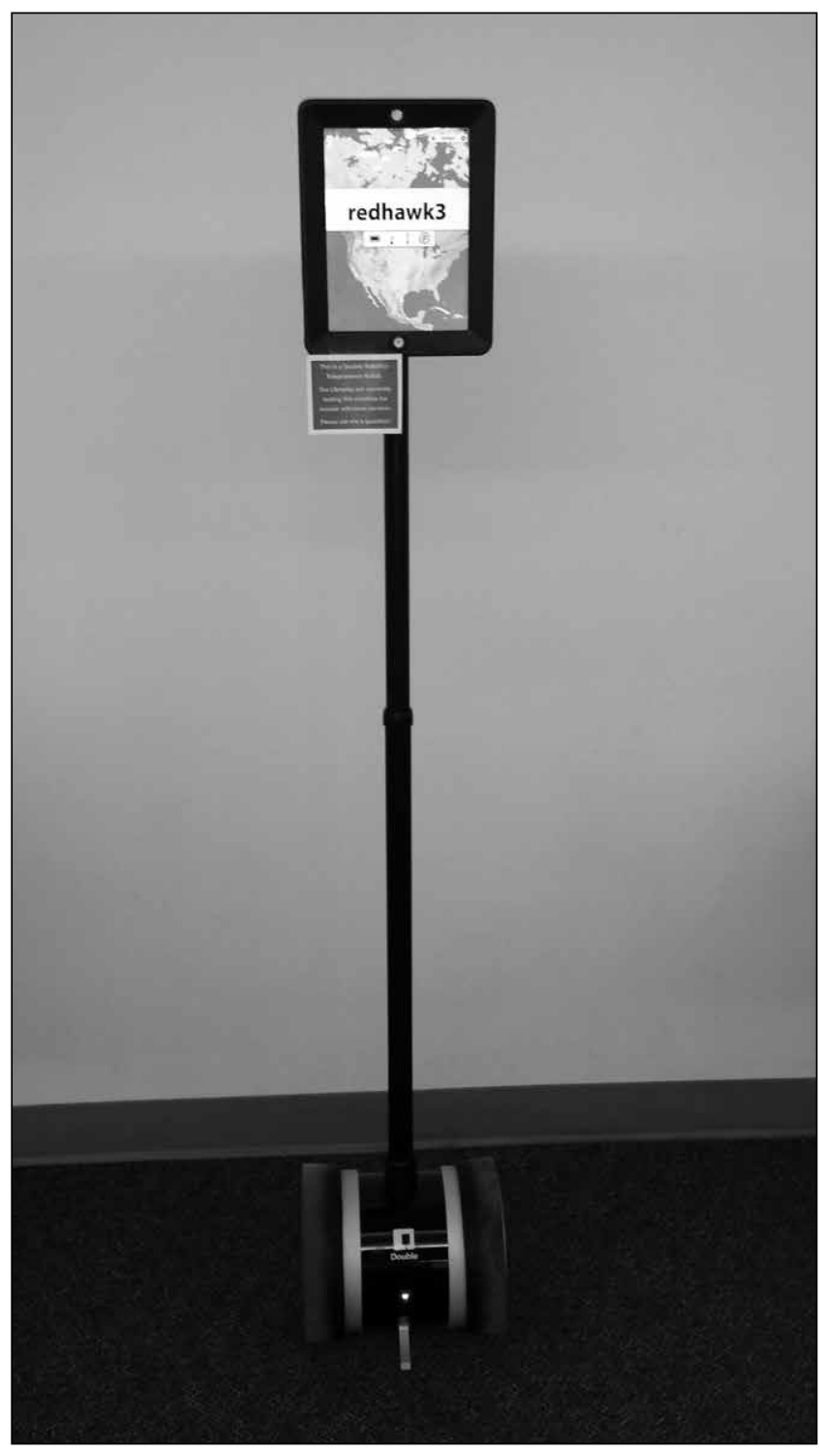

Figure 1. Double Robotics telepresence robot

\section{WHAT WORKED}

Overall the robot functioned well, with a simple interface and adequate battery life. Battery life of the robot was sufficient for a full day of use and the robot can be parked using a builtin kickstand to conserve power. The base is easily charged overnight and Double Robotics sells a parking stand that can charge the robot during the day. Initial concerns about security proved unfounded. No attempts at theft or malicious activity were encountered. Stolen iPads are lockable via iOS settings, and findable via "find my iPhone" functionality.

As a telepresence machine (providing real-time two way video communication) this system functioned well overall. However, the goal was to see if the robot could be useful in a library setting for patron interaction and potentially beyond simple telepresence. The results of our test period were not promising. 


\section{FEATURE}

\section{LIMITATIONS}

The limitations of the platform for the type of tasks we were hoping to accomplish were many. Issues regarding connectivity, limited software, mobility, iPad battery life, volume, and patron privacy were encountered throughout the trial period.

The most commonly encountered problem with the robot was connectivity. The software used to connect to the robot can run over any Internet connection (wi-fi or 3G/4G), depending on the hardware in the iPad. Through various parts of the library, such as in the stacks, narrow hallways, and highly trafficked areas with many devices connected to a single wi-fi access point the connection would drop unexpectedly requiring that the operator either wait for the connection to reestablish itself or manually retrieve and move the robot to another location with a stronger signal. The connection functioned more smoothly in the other libraries we tested, and the other departments on campus who have been testing robots have not had similar connection issues. Connectivity issues at King Library could be due to a high volume of use. It is one of the most highly trafficked buildings on campus and during the day can have hundreds of people using wi-fi. However connectivity problems were not severe enough to significantly impact the trial and were probably due to the library's physical structure and intense network traffic, and not to the robot itself.

The simplicity of the software and hardware meant that the robot was easy to use. However this simplicity meant limitations in functionality. The robot could not show additional screens to the patron (such as the library website or databases), did not allow for the patron to push additional information to the librarian, or to interact with or run other apps on the iPad. The limited functionality of the iPad negates the benefits of deploying mobile devices with librarians. A greater benefit for patrons would be a roving librarian simply carrying an iPad, able to look up resources at the point of contact. The robot possesses no means of physically interacting with its environment: it cannot push elevator buttons, move books, or transport anything to or from a patron.

One of the most common questions from patrons involves physically locating books on the shelves. The movement capabilities of the platform made this task almost impossible. The robot's limited speed, range of vertical motion, and direction of movement meant that it could look at only a small area of shelving. The two lowest and three highest shelves in any range were unreachable by the iPad camera (the mast can be raised and lowered between 47" and 60"). The robot is not capable of lateral movement or looking sideways and so would have to be constantly repositioned at each new section of shelving. Additionally the operator sees through the front-facing, lower-resolution camera of the iPad making for a blurry picture and hard-to-read text. The fixed mounting of the iPad does not allow the camera to be canted at an angle. What the operator sees while driving can be switched to the back-facing camera, which through a mirror lets the operator see obstacles on the floor while driving but is otherwise useless for locating materials. While the interface is straightforward, the actual driving requires a fair bit of concentration, shifting the focus of the librarian from the patron to the robot and limiting flexibility in locating resources.

The robot must be driven manually. Double Robotics provides an API (application programming interface) that can be used to write software for the system, but no ability for routes to be programmed or automated guidance are provided. This lack of automation renders the machine nonviable as a potential automatic tour guide, book retriever, or scout for open study space. Even if such autonomous functions were available they would not be able to help a patron in information seeking.

While the battery life of the wheeled base did not pose a problem, battery life for the iPad did. The iPad runs off its internal battery and the base has no ability to supplement it. The iPad runs software that allows the base to balance and be driven remotely as well as the video and audio telepresence connection. Simply having the robot standing in place with an open connection for six hours saw the iPad battery almost completely drained, even without many conversations or much movement. Testing of longer conversational interactions and significant amounts of driving drained the battery to the point of necessitating a recharge during the day. Having more than one iPad dedicated to the robot would be necessary if the system were to see extensive use.

There is no function in the app running on the robot to establish a call to the operator. Thus for a patron to ask a question, the connection must be open. This need for an open connection essentially amounts to a live feed of the actual librarian operator on the robot throughout the entire day. The librarians manning the machine were in their offices and on the information desk during the trial but found this situation a bit limiting of other activities (phone calls, office consultations) and somewhat disconcerting. During the trial the robot was available for patrons to come up to and ask questions. Additionally the libraries' website provided instructions for requesting the robot through the online chat system or by phone.

Patron privacy is also a potential issue. When the robot was stationary in a lobby-like area, groups of chatting people would come by oblivious to the fact that someone could be listening in on their private conversations. The microphone on the iPad is sensitive enough to register nearby conversations and while the connection can be muted, doing so means that someone coming up to the robot would not be heard by the operator. The operator can see the feed while it is muted, but this requires constant visual monitoring. While this is a low-level activity, it proved to be distracting throughout the day.

Carrying on conversations with patrons can also be an issue in quiet study areas. Patrons are quite serious when it comes to maintaining silence in designated quiet study areas. Whether in-person or through a robot, audible conversation is not appreciated. Setting the volume loud enough to 
communicate through the iPad's speaker resulted in "Shh, don't disturb me" looks from patrons in the quiet study areas, which make up a large amount of floor space in King Library.

The ultimate limitation of using a system like this for reference service is that the librarian running it will likely be located in the same building as the robot. As a means of remotely speaking with a librarian, the robot functions well. However, after the initial establishment of the conversation, interactive service with the platform is limited. Beyond simply talking to a patron, we failed to identify any task that could not be accomplished more effectively and quickly in person. Even as a means of allowing a librarian to continue manning a desk while performing a task elsewhere in the building, using the robot proved distracting (negating any benefit of staying at the desk) and ultimately more time consuming than simply "roving" around.

\section{PATRON REACTION}

Patrons generally responded favorably to the presence of the robot, if they were the ones to initiate an interaction with it. While the robot was stationed in the library, patrons would often come up to it and ask what it was and what it was for, although such walk-up interactions only garnered a single reference question during the trial.

However, to make the robot's presence more visible, we experimented with driving it around the library, careful to respect patron's privacy and personal space. Reactions were decidedly not positive.

The robot makes almost no noise while moving. Even extended to its highest, its slim profile and dark color make it hard to see. Combined with the fact that the iPad presents only the face of the operator, it makes for a confusing interface if you do not know what to expect from it. When interacting with patrons during these times, the machine was generally met with negative responses ranging from simply startling patrons to eliciting some colorful language regarding "getting that thing away from me." These reactions indicate that a system such as this robot would not be beneficial in helping a roving librarian reach patrons without further education of patrons as to the purpose of the system

During a library instruction class the robot was presented as a potential tool for the future of remote interaction. Students either had generally positive reactions or didn't notice the thin black robot standing at the front of the classroom. Students were later asked to imagine how a robot could be used in the library. Student responses for potential uses of the robot included scanning the library for open study carrels, directing students to books or other locations, as a check-out kiosk, and library page tasks like fetching books. Students also suggested that the robot would be useful for patrons who did not want to leave their desks and lose their study space, but needed research help.

Directing students to books is accomplished more quickly in person. The robot cannot retrieve books. Check-out kiosks and catalog look-up stations are available at fixed locations throughout the stacks and lobby. Driving the robot to look for study space is significantly slower than walking. The library also offers a lobby display of open computers using LabMaps software (www.labstats.com/Solutions/LabMaps). Additionally the idea of personal direction to an open desk was not judged to be an appropriate use of a librarian's time. While anecdotal student feedback generally followed what we had hoped the robot would be useful for, the limitations of the Double Robotics Telepresence Robot precluded its usefulness for these tasks.

\section{CONCLUSIONS}

Telepresence in the form of a robot does not seem to be as yet an adequate platform for reference services. While the machine performed as advertised, we were not able to stretch its physical abilities to the services provided or expected in a library. Even the most basic interactions would require more robust software that allows for sharing resources between the patron and librarian, as well as more robust hardware that could move faster, in more directions, with some ability to manipulate its environment.

It may be possible to extend the capability of the system by using other technologies to shore up areas where the system is lacking. Extended batteries could lengthen the useful life of the system. Initially we had planned to offer a remote call service through the library website that would allow patrons to request the robot come to them, however we were not able to implement such a system during the trial. Such a system would allow patrons to request the presence of the robot from anywhere in the building. Tagging of library materials using RFID technology coupled with an onboard scanner could allow the robot to direct patrons to materials without having to visual identify items. Using more robust tablets or "ultrabook" type laptops could provide more options for interaction between patron and operator (keyboards, two-way web searching, screen sharing).

While the robot hardware used in this trial didn't live up to expectations, telepresence as a means of providing reference service seems to be promising. We will be experimenting further with offering video chat as a channel for remote reference service in the future, based on our few positive interactions using the robot. We felt that the ability to have face-to-face interaction with patrons at any location was the most potentially beneficial result of the trial.

While iPads and other mobile technologies can extend the reach and capabilities of librarians at and away from the reference desk, our time with this robot would seem to indicate that the librarians in the building won't be replaced any time soon, and the remote reference services currently on offer seem to meet patrons' needs. Roving reference is meant to connect librarians with users. Utilizing new information technologies is a way to extend the capabilities of librarians. While some aspects of this trial showed promise (telepresence) 


\section{FEATURE}

the hardware was found lacking and to be an unnecessary and cumbersome layer between librarian and patron. A system that could more seamlessly integrate telepresence with extended information seeking capabilities could be of great use in reaching patrons in and beyond the library.

\section{References}

1. Maximizing Library Storage with High-Tech Robotic Shelving, Journal of Academic Librarianship 31, no. 2 (2005): 172.

2. J. Kountz, "Robots in the Library: Automated Storage and Retrieval Systems," Library Journal 112, no. 20 (1987): 67. M. Parry, "A High-Tech Library Keeps Books at Faculty Fingertips-With Robot Help," Chronicle Of Higher Education 57, no. 42 (2011), A12-A13.

3. "Robot Digitizes Old Books," Information Management Journal 42, no. 1 (2008): 14.
4. W. Lin et al., "Developing a Service Robot for a Children's Library: A Design-Based Research Approach," Journal Of The Association For Information Science \& Technology 65, no. 2 (2014): 290-301, http://dx.doi.org/10.1002/asi.22975.

5. Kathryn Zickuhr and Lee Rainie, "Tablet and E-reader Ownership," Pew Research Center, January 16, 2014, www.pewinternet .org/2014/01/16/tablet-and-e-reader-ownership.

6. Aaron Smith, "Smartphone Ownership 2013," Pew Research Center, June 5, 2013, www.pewinternet.org/2013/06/05/smartphone-ownership-2013.

7. K. Penner, "Mobile Technologies and Roving Reference," Public Services Quarterly 7, no. 1/2 (2011): 27-33. J. Gadsby and S. Qian, "Using an iPad to Redefine Roving Reference Service in an Academic Library," Library Hi Tech News 29, no. 4 (2012): 1-5.

8. E. H. Kramer, "Why Roving Reference: A Case Study in a Small Academic Library," Reference Services Review 24, no. 3 (1996): 67.

9. M. M. Smith and B. A. Pietraszewski, "Enabling the Roving Reference Librarian: Wireless Access with Tablet PCs," Reference Services Review 32, no. 3 (2004), 249-55. 